\title{
What is New in Pediatric Maxillofacial Fractures? - A Systematic Review
}

\author{
Abdul Wadood Mohammed* \\ Department of ENT, King Faisal University, Saudi Arabia
}

Submission: April 24, 2017; Published: May 04, 2017

*Corresponding author: Abdul Wadood Mohammed, Assistant Professor, Department of ENT, College of Medicine, King Faisal University, Al Hassa, Saudi Arabia, Tel: 00966504673230; Email: wadood_abd@yahoo.co.in; wadood83@yahoo.com

Abstract

Pediatric maxilla facial fractures are rare compared to adult maxilla facial injuries. However, they follow a different pattern of presentation and management principles. As the facial bones in children are in the developing stage, they have to be managed using the most conservative methods possible. Since children have a less hemodynamic reserve, other serious injuries have to be also dealt simultaneously. Many centers do not have a specialized pediatric trauma care system, hence, it is important for any emergency care personnel to know the principles behind managing such case. The article provides a systematic review of the recent articles in English literature on management of pediatric maxillofacial fractures.

\section{Introduction}

As the face is the most prominent part of the body, maxillofacial injuries are common in poly trauma. The presence of vital organs like eyes, nose, ear and susceptibility for airway obstruction mandates thorough knowledge of management of maxilla facial injuries. Pediatric maxillo-facial injury though rare, present with a different set of problems compared to adult maxilla-facial trauma. It is estimated that less than $1 \%$ of the maxillofacial trauma occur in children less than 5 years of age [1]. Children differ from the adults in their anatomic and physiologic makeup and hence require a different set of guidelines for management. As the facial skeleton would be in growing period, great care should be given to early management. Factors like the greater flexibility of bones, underdeveloped sinuses, unerupted teeth, the presence of protective fat pad and less involvement in high-velocity road traffic accidents make children less prone for injury [2].

\section{Materials and Methods}

The systematic review of the English literature was done using Pubmed from January 2000 to January 2016. The search was done using key term paediatric maxillofacial fractures. Articles like case reports, case series, general articles, chapters, and letter to editor, opinions and those articles before 2000 were excluded. Relevant articles from the reference of these articles, which followed the above criteria, were included.

\section{Results}

The search revealed 50 articles. Excluding case reports, case series, general articles, chapters, letter to the editor, opinions and those article before 2000, 20 studies were included in the review. 2 articles were added from the references of these articles. This included one systematic review, 19 retrospective analysis and 2 prospective analysis. According to the topic, 10 papers dealt with maxillofacial trauma, 2 papers on ocular trauma, 5 on mandibular fractures, one on nasal bone fracture, 1 on fronto-basilar fracture and one on dental fracture (Figure 1).

\section{Discussion}

\section{Maxillo facial trauma}

The data from 9 retrospective analysis of paediatric maxilo facial analysis was reviewed (Table 1). All the studies unanimously showed an increased incidence in the male children with an incidence ratio of 1.1:1 to $6.8: 1$. This could be due to more involvement in outdoor sports and more tendency towards violent behavior. There is no uniform consensus for the most common etiology of maxilla facial fracture in children. However, falls and motor vehicle accident were the two most common causes. The variation in etiology may be related to the geographic area of study. In rural areas, which are densely populated with poverty and substance, abuse the etiologies like falls and assault may predominate. In urban area with high- 
speed traffic, motor vehicle accidents will be the main etiology. Jung et al. [3] also noted that there is an evolution of the etiology with age of the child. Falls are common in younger children and motor vehicle more common in older children. Study by Iida et al. [4] also supported this observation and found that falls were common in children more than 11 years and sports related injuries more common in children more than 13 years of age.

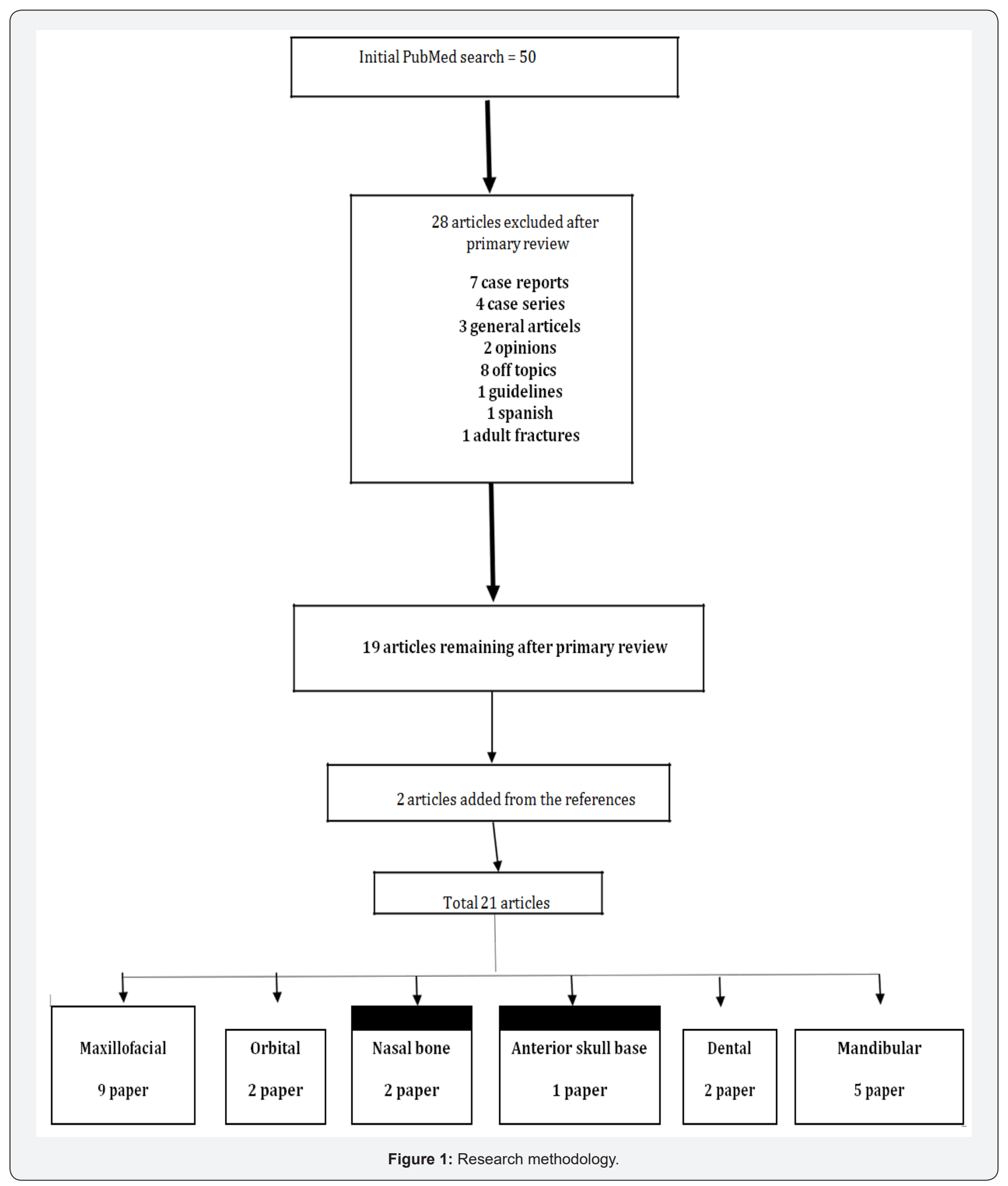


Table 1: Articles reviewed in the study.

\begin{tabular}{|c|c|c|c|c|c|}
\hline Name & Sex (Male: female) & $\begin{array}{l}\text { Most common } \\
\text { type }\end{array}$ & Most common Etiology & $\begin{array}{l}\text { Most common } \\
\text { Treatment }\end{array}$ & Other observation \\
\hline Jung [3] & $2: 1$ & NA & Fall > MVA & NA & $\begin{array}{l}\text { Falls more common } \\
\text { in younger children, } \\
\text { MVA more common } \\
\text { in children }\end{array}$ \\
\hline Iida [4] & $2: 1$ & Mandible & Bicycle accident/falls & OR in $46.5 \%$ & $\begin{array}{c}\text { Falls }>\text { less than } 11 \\
\text { year Sport }>\text { more } \\
\text { than } 13\end{array}$ \\
\hline Al Shetawi [6] & $6.8: 1$ & Mandible & Assault/pedestrian/fall & Conservative & $\begin{array}{c}\text { Other injury } 73 \% \text {, } \\
\text { MC concussion }\end{array}$ \\
\hline Burlini $[7]^{*}$ & NA & NA & NA & NA & NA \\
\hline Nardis [8] & $1.8: 1$ & Nasal & Falls $>$ violence $>$ bicycle $>$ MVA & $\begin{array}{l}\text { Conservative /closed } \\
\text { reduction }\end{array}$ & NA \\
\hline Bharadwaj [9] & NA & NA & Falls & $\begin{array}{c}\text { Observation } \backslash \mathrm{CR} \text { - } \\
\text { minimally displaced } \\
\text { OR-displaced }\end{array}$ & NA \\
\hline Okoje [10] & $1.1: 1$ & Mandible & RTA \gun shot & & NA \\
\hline Iatrou [11] & & Mandible & & $\begin{array}{c}\text { OR in } 66.8 \% \mathrm{CR} \text { in } \\
33.2 \%\end{array}$ & NA \\
\hline Arvind [12] & $2: 1$ & Mandible & MVA $>$ falls $>$ sports & NA & NA \\
\hline
\end{tabular}

NA: Not Available, MVA: Motor Vehicle Accident, CR: Closed Reduction, OR: Open Reduction, >: More Than, * this study specifically focused on use of resorbable material for repair.

In majority of studies mandible was the most common bone to be fractured, which is different from that of adults where nasal bone is the most common site. This could be due to the more projection of mandible compared to nasal pyramid in children. Another reason could be the incomplete ossification of the nasal bone leading to errors in image interpretation [5]. There is variation among the treatment modality used in different studies. However, this could be easily explained by the severity of injury dealt by them. The consensus was that children mostly present with undisplaced or minimally displaced fracture and hence required only observation or closed reduction. Only in severely comminuted cases or those fractures not reducing with closed reduction required open reduction and internal fixation.

It is important to remain conservative as much as possible as surgical intervention can also affect the maxillofacial growth. Al Shetawi et al. [6] noted that $73 \%$ of patient were associated with significant amount of other injuries, most common being concussion injury of the brain. This point to the need for a multidisciplinary approach to pediatric trauma care including a neurosurgeon and intensivist. Burlini et al. [7] compared the use of resorbable and conventional materials for repair and concluded that there was no significant difference in the incidence of complications and suggested that resorbable materials be used as it does not require further operation for removal [8-12].

\section{Mandibular fracture}

According to some studies, mandibular fractures are among the most common pediatric facial skeletal fractures having and incidence ranging from $21 \%$ to $73.9 \%$ in some regional studies [13,14]. A retrospective review by Siwani et al. [15] highlighted the role of mental disorders in sustaining injury and the need for multidisciplinary team including a psychologist for their management. They also concluded that conservative management would suffice in majority of cases. In another study by Fasola et al. [16], the etiology of fracture changed with age. According to the study, falls were the most common etiology in children below 11 years whereas sports related injuries were more common in children above 11 years and assault in children more than 13 years. A prospective study by Singh et al. [17] showed better outcome and lesser problems associated with corrosion when bio resorbable plates were used instead of metallic plate. Mandibular condyle fracture is considered as the most common mandibular fracture in children with the incidence ranging from $28-62 \%$.

In contrast to adults, condylar fracture should be properly managed in children, as improper treatment would lead to malocclusion and temporomandibular joint dysfunction. However, this can occur with surgical intervention also. Zhao et al. [18] advises the use of removable occlusal splint for conservative management and Wu et al. [19] suggested the use of screw-based semi-rigid inter maxillary fixation along with an occlusal splint for safe and easy treatments of pediatric condylar fracture.

\section{Ocular injury}

The only systematic review related to the topic was done by Dubois et al. [20]. The study reviewed 17 studies regarding the 
effect of timing on the outcome of orbital reconstruction. The study concluded that there is limited evidence to provide basis for appropriated timing for reconstruction and the evidence for early reconstruction is limited to retrospective analysis and expert opinions. A retrospective analysis by Gerber et al. [21], which included 24 patients, evaluated the outcome of orbital fractures and concluded that for better outcome the repair should be done early as possible. According to the study, a trapdoor injury needs urgent repair within 12 to 24 hours and an open blow out fracture should be explored within 3 days for optimum outcome. In contrast with the adult population, the complication rates increased when there was a delay in repair.

\section{Nasal bone fracture}

A study by Yilmaz et al. [22] suggested early reduction of pediatric nasal bone fractures associated with better satisfaction rate. They also suggested that closed reduction should be performed wherever possible and if open reduction is indicated, it should be as conservative as possible. However, another retrospective analysis by Lee et al. [23] found that pediatric nasal bone fractures had better outcome compared to adult fractures, regardless of their timing of repair.

\section{Anterior skull base fracture}

Fractures of the anterior skull base are very common in poly trauma cases and there is very little literature in pediatric anterior skull base fractures. In the retrospective review by Schaller et al. [23], high-speed motor vehicle accident was the most common cause for frontal basal skull base fracture. The commonly observed complications were pneumocranium, visual loss, and cerebrospinal fluid leak from the nose. The conclusion of the study was that as skull base fractures were associated with high degree of brain injury and other multisystem involvement, management of the patient in a high dependency unit with the help of a multisystem team is essential to reduce morbidity and mortality.

\section{Dental injury}

Dental trauma is often a neglected part of a poly trauma scenario. This may be due to it's relatively non-life threatening nature. Very few studies have discussed this subject in detail. A regional study by Kovacs et al. [24] found that there was a difference in the etiology for trauma to primary and secondary dentition. The common etiology for trauma to primary dentition was falls during learning to walk and secondary dentition was sports and bicycle injuries. Another study by Hasan et al. [25] found that the most common teeth affected were the maxillary primary central incisors.

\section{Conclusion}

Pediatric maxilla facial injury is a very important subset of trauma care. Due to the developmental nature of the facial bones, it follows a different set of principles in management [26]. Early intervention with conservative approaches should be the most important priority while managing maxillofacial injury in children. Use of resorbable materials for repair should also be promoted to prevent the need for reexploration. The role of multi-disciplinary team should also be further studied.

\section{References}

1. Haug RH, Foss J (2000) Maxillofacial injuries in the paediatric patient. Oral Surg Oral Med Oral Path 90(2): 126-134.

2. Ferreira PC, Amarante JM, Silva PN, Rodrigues JM, Choupina MP, et al. (2005) Retrospective study of 1251 maxillofacial fractures in children and adolescents. Plast Reconstr Surg 115: 1500-1508.

3. Jung TK, De Silva HL, Konthasingha PP, Tong DC (2015) Trends in paediatric maxillofacial trauma presenting to Dunedin Hospital, 2006 to 2012. N Z Dent J 111(2): 76-79.

4. Iida S, Matsuya T (2002) Paediatric maxillofacial fractures: their aetiological characters and fracture patterns. J Craniomaxillofac Surg 30(4): 237-241

5. Rowe NL, Killey HC (1986) Fractures of the facial skeleton. Willians \& Wilkins Co, Baltimore, USA.

6. Al Shetawi AH, Lim CA, Singh YK, Portnof JE, Blumberg SM (2016) Pediatric Maxillofacial Trauma: A Review of 156 Patients. J Oral Maxillofac Surg 74(7): 1420.

7. Burlini D, Conti G, Amadori F, Bardellini E, De Giuli C (2015) Management of paediatric maxillofacial fractures: conventional methods and resorbable materials. Eur J Paediatr Dent 16(1): 24-28.

8. Nardis Ada C, Costa SA, da Silva RA, Kaba SC (2013) Patterns of paediatric facial fractures in a hospital of São Paulo, Brazil: a retrospective study of 3 years. J Craniomaxillofac Surg 41(3): 226-229.

9. Bhardwaj Y, Kumar D. Pediatric Maxillofacial Trauma Outcomes Based on a Survey of 65 Patients: A Prospective Study of Etiology, Incidence and Methods of Treatment. J Maxillofac Oral Surg 14(3): 687-692.

10. Okoje VN, Alonge TO, Oluteye OA, Denloye OO (2010) Changing pattern of pediatric maxillofacial injuries at the Accident and Emergency Department of the University Teaching Hospital, Ibadan--a four-year experience. Prehosp Disaster Med 25(1): 68-71.

11. Iatrou I, Theologie-Lygidakis N, Tzerbos F (2011) Surgical protocols and outcome for the treatment of maxillofacial fractures in children: 9 years' experience. J Craniomaxillofac Surg 38(7): 511-516.

12. Arvind RJ, Narendar R, Kumar PD, Venkataraman S, Gokulanathan S (2013) Maxillofacial trauma in Tamil Nadu children and adolescents: A retrospective study. J Pharm Bioallied Sci 5(Suppl 1): S33-35.

13. BL McGraw, RR Cole (1990) Pediatric maxillofacial trauma: age-related variations in injury Arch. Otolaryngol Head Neck Surg 116(1): 41-45.

14. H Thorén, P Iso-Kungas, T Iizuka, C Lindqvist, J Törnwall (2009) Changing trends in causes and patterns of facial fractures in children. Oral Surg Oral Med Oral Pathol Oral Radiol Endod 107(3): 318-332.

15. Siwani R, Tombers NM, Rieck KL, Cofer SA (2014) Comparative analysis of fracture characteristics of the developing mandible: the Mayo Clinic experience. Int J Pediatr Otorhinolaryngol 78(7): 1066-1070.

16. Fasola AO, Obiechina AE, Arotiba JT (2001) Fractures of the mandible in children. East Afr Med J 78(11): 616-618.

17. Singh G, Mohammad S, Chak RK, Lepcha N, Singh N, Malkunje LR (2012) Bio-resorbable plates as effective implant in paediatric mandibular fracture. J Maxillofac Oral Surg 11(4): 400-406.

18. Zhao YM, Yang J, Bai RC, Ge LH, Zhang Y (2014) A retrospective study of using removable occlusal splint in the treatment of condylar fracture in children. J Craniomaxillofac Surg 42(7): 1078-1082.

19. Wu Y, Long X, Fang W, Li B, Cheng Y, et al. (2012) Management of 
paediatric mandibular condylar fractures with screw-based semi-rigid intermaxillary fixation. Int J Oral Maxillofac Surg 41(1): 55-60.

20. Dubois L, Steenen SA, Gooris PJ, Mourits MP, Becking AG (2015) Controversies in orbital reconstruction-II. Timing of post-traumatic orbital reconstruction: a systematic review. Int J Oral Maxillofac Surg 44(4): 433-440.

21. Gerber B, Kiwanuka P, Dhariwal D (2013) Orbital fractures in children: a review of outcomes. Br J Oral Maxillofac Surg 51(8): 789-793.

22. Yilmaz MS, Guven M, Kayabasoglu G, Varli AF (2013) Efficacy of closed reduction for nasal fractures in children. Br J Oral Maxillofac Surg 51(8): e256-258.

23. Dong Hwan Lee, Yong Ju Jang (2013) Pediatric nasal bone fractures:
Does delayed treatment really lead to adverse outcomes? Int J Pediatr Otorhinolaryngol 77(5): 726-731.

24. Schaller B, Hosokawa S, Büttner M, Iizuka T, Thorén H (2012) Occurrence, types and severity of associated injuries of paediatric patients with fractures of the frontal skull base. J Craniomaxillofac Surg 40(7): e218-221.

25. Kovacs M, Pacurar M, Petcu B, Bukhari C (2012) Prevalence of traumatic dental injuries in children who attended two dental clinics in Targu Mures between 2003 and 2011. Oral Health Dent Manag 11(3): 116-124.

26. Hasan AA, Qudeimat MA, Andersson L (2010) Prevalence of traumatic dental injuries in preschool children in Kuwait - a screening study. Dent Traumatol 26(4): 346-350.

\section{Your next submission with Juniper Publishers will reach you the below assets}

- Quality Editorial service

- Swift Peer Review

- Reprints availability

- E-prints Service

- Manuscript Podcast for convenient understanding

- Global attainment for your research

- Manuscript accessibility in different formats

( Pdf, E-pub, Full Text, Audio)

- Unceasing customer service

Track the below URL for one-step submission https://juniperpublishers.com/online-submission.php 